\title{
Top-down Processing in Four-skills Integrated Computer-Assisted Language Learning
}

\author{
Hiroki Yoshida
}

\begin{abstract}
Computer-Assisted Language Learning (CALL) has developed along with the rapid advancement of computers. Therefore, the characters and techniques of CALL reflect the development of technology. Current technology innovations provide teachers and students various authentic sources for teaching and learning all of the four skills in CALL. This study purposed to examine the effectiveness of top-down processing in four-skills integrated CALL. Results of the study suggest that top-down processing in four-skills integrated CALL enhances English language proficiency, knowledge and attitude of Japanese university students at intermediate level.
\end{abstract}

Keywords-Computer-assisted Language Learning (CALL), Top-down Processing, Four-skills Integrated Approach, Semantic Network, English as a Lingua Franca (ELF), Technology Enhanced Language Learning (TELL)

\section{INTRODUCTION}

The development of technology has enabled more and more language teachers and learners to use technologies such as computer and the Internet for language teaching and learning. Technological innovations such as the Internet have allowed people communicate with others easily and instantly. Along with the global spread of English as a Lingua Franca (ELF) and/or World Englishes (WE), the rapid evolution of technology has been impacting theory and practice of language teaching and learning.

\section{A. Computer-Assisted Language Learning}

Computer-Assisted language learning (CALL), i.e. Technology Enhanced Language Learning (TELL) has been used in second/foreign language classes since the 1960s [1]. CALL is defined by Levy as "the search for and study of applications of computer in language teaching and learning" [2] Since CALL/TELL has developed along with the rapid advancement of computers, the characters and techniques of CALL/TELL reflect the development of technology. Warschauer [3] divides the development of CALL into three phases: 1) behavioristic CALL which is conducted in a "drill and practice" model and considered a sub-component of computer-assisted instruction (CAI), 2) communicative CALL which provides skill practice in a non-drill format, and

Hiroki Yoshida, College of Intercultural Studies, Kanto Gakuin University Yokohama, Japan integrative CALL which makes full use of multimedia technologies and the Internet.

Current technology provides teachers and students various authentic sources for teaching and learning all of the four skills (reading, writing, listening, and speaking) of language. Previous studies suggest that CALL has positive effects of students' reading comprehension [4], [5], writing skills [6], [7], listening comprehension [8], [9], and speaking skills [10], [11]. It is also suggested that CALL leads to increase learners' autonomy [12], [13], motivation [14], [15], attitude toward English [15-17], and self-efficacy toward use of English [16], [18].

\section{B. Four-skills Integrated Approach in Japanese Schools}

Primary and secondary school teachers in Japan develop school curricula and classroom lessons based on the national education guideline "Course of Study." The Regulations for the Enforcement of the School Education Act that were notified in 1947 states that primary and secondary schools' curricula must meet standards established by the Minister of Education in its Course of Study.

The first Course of Study was announced in 1947 and since then, it has been revised seven times. In 2008, the present Course of Study was announced with the emphasis to cultivate students' "zest for life," by balancing attainment of basic knowledge and skills with thinking skills, decision-making skills, and expression skills, and to nurture rich and wholesome heart and body [19]. The current Course of Study sets the overall objective for Foreign Languages as follows:

“To develop students' basic communication abilities such as listening, speaking, reading and writing, deepening their understanding of language and culture and fostering a positive attitude toward communication through foreign languages (overall objective for lower secondary school) [19]."

"To develop students' communication abilities such as accurately understanding and appropriately conveying information, ideas, etc., deepening their understanding of language and culture, and fostering a positive attitude toward communication through foreign languages (overall objective for upper secondary school) [20]."

In order to achieve these goals, the English curriculum for secondary education was reconstructed. While the previous Course of Study aimed to develop each of the four skills area (speaking, listening, writing, and reading) separately in different subjects [21], the present Course of Study adopts a four-skills 
integrated approach with the emphasis of teaching English for communication purposes.

The current Course of Study for lower secondary schools was revised and announced in March, 2017, and is going to be in force on April 1st, 2021 [22]. The Course of Study for upper secondary schools is under revision. In the next Course of study, five domains/four-skills approach: listening, reading, speaking (interaction), speaking (presentation), writing is going to be adopted.

Thus, four-skills integrated approach is being implemented in Japanese schools.

\section{C.Top-down Processing and Semantic Networks}

The schema theory describes how learners' background knowledge interacts with the learning material. Huang notes that "according to schema theory, any text, spoken or written, does not by itself carry meaning. Comprehending words, sentences, and entire texts require the ability to relate the material to one's own knowledge [23]." According to Numan, "schema theory is based on the notion that past experiences lead to the creation of mental frameworks that help us make sense of new experiences [24]." That is, learners' prior knowledge enables them to make predictions to understand the text.

In ELF, the role of the teacher is important to activate and construct students' schemata on the learning material. The teacher's first task is to select learning materials that are relevant to students' experience, prior knowledge and interest. After selecting learning materials, the teacher designs activities that can be used to activate and construct learners' schemata. In top-down processing ELF, the pre-learning stage is the most important stage to activate students' schemata. According to de Debat, students' schemas are activated by "having students think, write and discuss everything they know about the topic, employing techniques such as prediction, semantic mapping, and reconciled reading [25]."

On contrast, in the bottom-up approach, the learning process "proceeds in serial fashion, from letter to sound, to words, to meaning [26]."

Top-down processing and bottom-up processing seem to match different type of learners. It is noted that top-down processing is not useful for language learners at elementary levels [27], while top-down processing is not useful for language learners at advanced levels [28].

In this study, semantic networks were used to activate students' content schemata, and to assess students' knowledge on a specific topic. Johnson and Pearson [29] claims that various components of schemas are arranged in networks of interrelated concepts, and words are labels for concepts. Therefore, it can be assumed that words are stored in semantically related networks. Semantic networks are knowledge representation tools consisted of nodes and links. Nodes represent knowledge or concepts, and links represent relations between the concepts.

\section{II.PURPOSE}

The purpose of the study is to examine the effectiveness of top-down processing in four-skills integrated CALL.

The research questions to be addressed in this paper are:

1) What effects do top-down processing have on students' English language proficiency in four-skills integrated CALL?

2) What effects do top-down processing have on students' attitude in four-skills integrated CALL?

\section{METHOD}

The study was conducted from April, 2017 to January, 2018, with the purpose of identifying the effects of top-down processing in four-skills integrated CALL.

\section{A. Participants}

Participants were 35 Japanese second-year university students (15 females, 20 males) who participated in CALL courses for two 15-weeks semesters. All of the students belonged to the Department of English Culture, College of Intercultural Studies, and took compulsory courses named "CALL Seminar" for two semesters. In order to examine the effectiveness of top-down processing in four-skills integrated CALL, the first semester was managed in a bottom-up approach, while the second semester was managed in a top-down approach.

\section{B. Lesson Design: First Semester}

The first semester CALL lessons were conducted in a bottom-up approach. Fig. 1 shows the flow of each lesson.

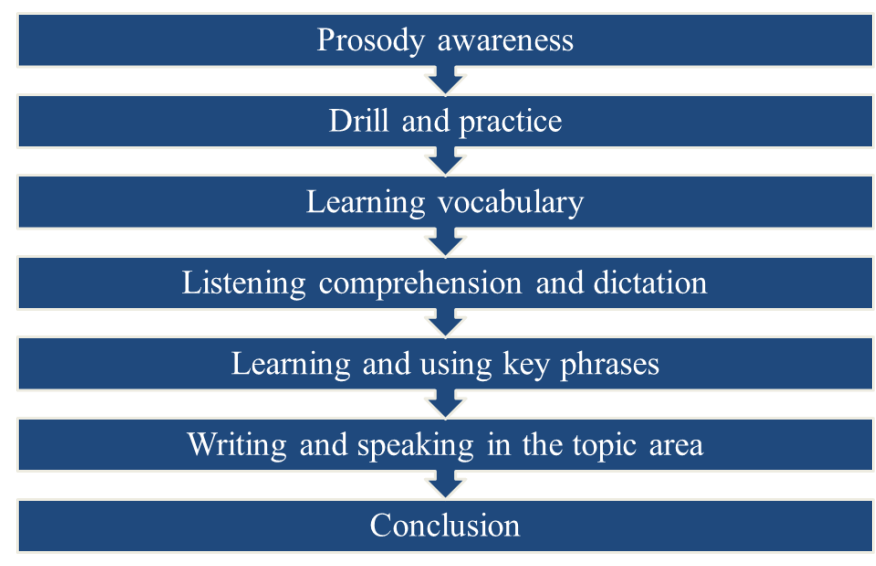

Fig. 1 Flow of the CALL lessons in a bottom-up approach (First semester)

In the bottom-up approach CALL course, the learning process proceeded from phonemes to prosody, to words, to phrases, to meaning.

\section{C.Lesson Design: Second Semester}

The second semester CALL lessons were conducted in a top-down approach. Fig. 2 shows the flow of each lesson. 


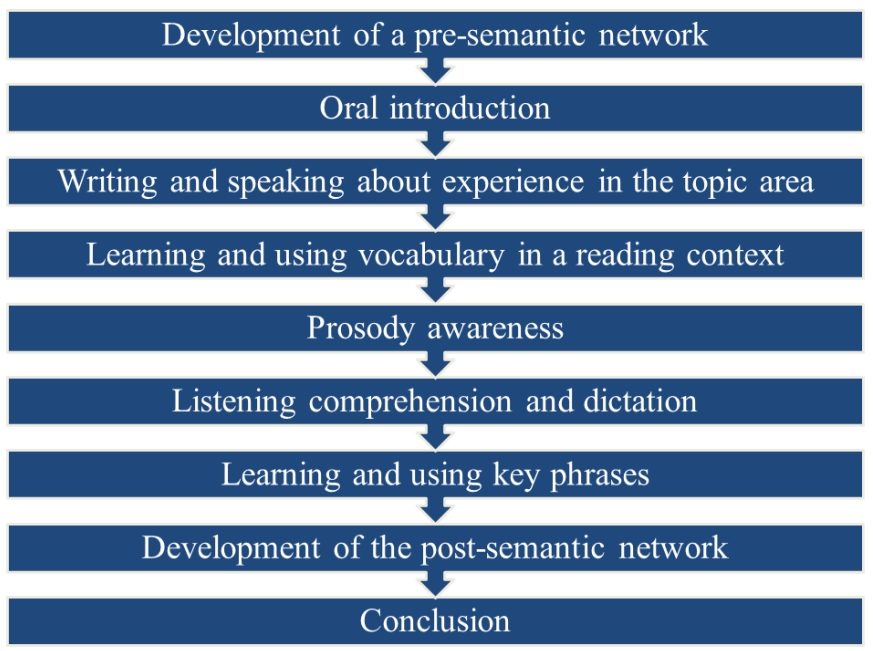

Fig. 2 Flow of the CALL lessons in a top-down approach (Second semester)

The contents of each element of the lessons are as follows.

\section{Pre-Post semantic network}

Participants were required to complete a pre-semantic network in advance of the activity in order to demonstrate how much knowledge they had on the lesson's topic before they worked on the CALL activities. Participants were required to complete a post-semantic network after the CALL activities in order to demonstrate how much knowledge they acquired through the activities. Figure 3 is an example of a semantic network developed by a participant.

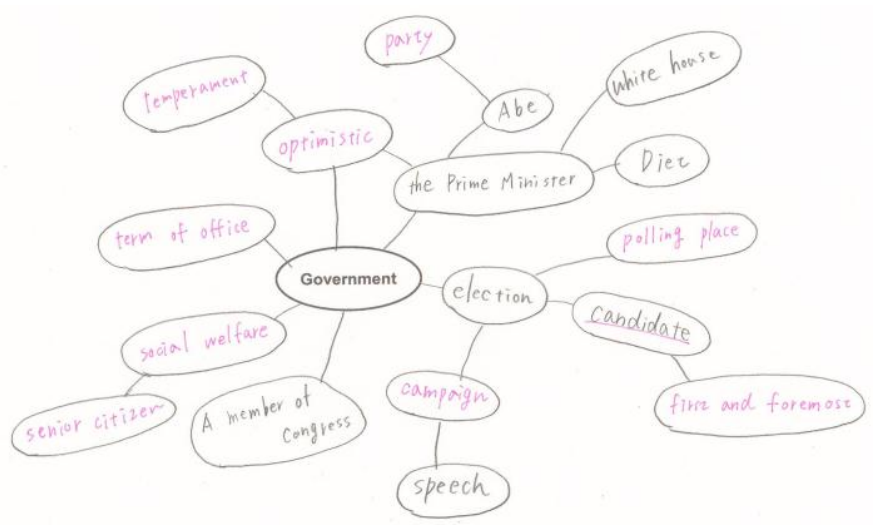

Fig. 3 Example of a semantic network developed by a participant

Participants wrote words in English in principle but they were allowed to write words in Japanese if they did not know how to express the word in English.

\section{Oral Introduction}

In order to introduce the lesson's topic and to activate students' content schemata, brief oral introduction on the lesson's topic was given by the lecturer at the beginning of the lesson. The following is an example of an oral introduction on the topic "movies."
"What kind of movies do you like? I like human dramas. My favorite movie is 'The Godfather.' The movie teaches us the importance of our family, and it illustrates the whole life of the 'Godfather' Michael Corleone. I watched this movie at a movie theater in my hometown Yokohama when I was a child. I used to go to the movies every month when I was a college student, but now, I don't have enough time to watch movies in the theater, so I watch movies at home. "

\section{Writing and speaking about experience in the topic area}

Students were asked a few questions and they wrote their experience in the topic area. Below is an example of questions students were provided.

"What kind of movies do you like? What is your favorite movie, and why do you like it? How often do you watch movies? Do you prefer going to the theaters or watching movies at home? "

Then, they were randomly assigned to pairs, and they shared their experience with each other via CALL application.

\section{Learning and using vocabulary in a reading context}

First, students learned new words/phrases related to the lesson's topic. For example, when the lesson's topic was "movies," students learned words/phrases such as "critic," "(movie) buff," and "(movie) trailer" in a short paragraph on "movies." Then, they used the words/phrases in context.

\section{Prosody awareness}

Students studied segmental features and suprasegmental features that were related with the new words/phases they learned in the lessons. Then they practiced segmental and supramental features through CALL application.

\section{Listening comprehension and dictation}

Students listened to two dialogues that were based on the lesson's topic. They answered to some multiple-choice questions about the dialogue, and filled in the blanks with words in the spot diction sheet provided by the CALL system.

\section{Learning and using key phrases}

Students learned key phrases that were related with the lesson's topic. These are examples of the key phrases students learned.

- "patterns to repeat what other people have said" such as "I heard about..." and "Some people say that..."

- "patterns to suggest that something is not being said by anyone" such as "I haven't heard about..." and "Nobody's saying that..."

Then, students chose one movie trailer and watched it. After they watched the trailer, students were randomly assigned to pairs and exchanged their opinions and feelings about the movie trailer they watched. 


\section{Course Evaluation Questionnaire}

A five item questionnaire on a five-point Likert scale ranging from 1 (strongly disagree) to 5 (strongly agree) was used to evaluate participants' attitude toward the CALL courses. The five questions were:

1. The contents of the course were interesting.

2. The contents of the course were understandable.

3. I acquired knowledge and skills via the course.

4. The difficulty of the activities was appropriate.

5. I am satisfied with the course on the whole.

\section{RESULTS}

Among the 35 participants, 33 completed the CALL courses. Hereinafter, results of the 33 participants' English language proficiency and participants' attitude toward the CALL courses will be introduced.

\section{A. Participants' Profile}

Table 1 shows the breakdown of participants by gender.

TABLE I PROFILE OF THE PARTICIPANTS

\begin{tabular}{l|l|r|c}
\hline \hline \multicolumn{2}{c|}{ Profile of participants } & F & $\%$ \\
\hline \hline \multirow{3}{*}{ Gender } & Female & 14 & $42.42 \%$ \\
& Male & 19 & $57.58 \%$ \\
\cline { 2 - 4 } & Total & 33 & $100.00 \%$ \\
\hline \hline
\end{tabular}

\section{B. Effects of Top-down Processing on Participants' English} Language Proficiency

Effects of top-down processing in four-skills integrated CALL were examined by comparing participants' English language proficiency at the end of the first semester (CALL in a bottom-up approach) and the second semester (CALL in a top-down approach). Participants' English language proficiency was assessed by English four-skills examinations that were conducted at the end of each semester. For evaluation of the differences, Student's one-tailed $t$-test was used.

Table 2 shows the effects of top-down processing in four-skills integrated CALL. Results indicate that participants' English language proficiency was significantly higher when they participated in a four-skills integrated CALL course which was operated in a top-down approach $(t(32)=5.00, \mathrm{p}<.00)$.

TABLE II EFFECTS OF TOP-DOWN PROCESSING ON PARTICIPANTS' ENGLISH

\begin{tabular}{l|r|r|r|c|c}
\multicolumn{7}{c|}{ LANGUAGE PROFICIENCY } \\
\hline \hline & $\begin{array}{r}\text { Sem 1, } \\
\text { mean, } \\
(\mathrm{SD})\end{array}$ & $\begin{array}{r}\text { Sem 2, } \\
\text { mean, } \\
(\mathrm{SD})\end{array}$ & $d f$ & $t$ & $P$ \\
\hline \hline $\begin{array}{l}\text { English language } \\
\text { proficiency }\end{array}$ & 60.30 & 66.58 & 32 & 5.00 & $<.00$ \\
\hline \hline
\end{tabular}

\section{Students' Attitude toward the CALL Courses}

Participants' attitude toward the CALL courses was evaluated by a five item questionnaire on a five-point Likert scale. Questionnaire surveys were conducted on July 10th and January 15 th, 2018.

Table 3 shows participants' attitude toward the CALL courses. The mean was calculated by giving each of the Likert scale points a number value, where strongly disagree $=1$, disagree $=2$, undecided $=3$, agree $=4$, and strongly agree $=5$. Results indicate that participants' interest, perceived understandability, perceived difficulty, and satisfaction toward the CALL course was higher when they experienced the top-down approach (first semester).

TABLE III PARTICIPANTS’ ATTITUDE TOWARD THE CALL COURSES

\begin{tabular}{l|r|r}
\hline \hline \multicolumn{1}{c|}{ Item } & Sem 1 & Sem 2 \\
\hline \hline $\begin{array}{l}\text { 1. The contents of the course were } \\
\text { interesting. }\end{array}$ & 3.9 & 4.1 \\
\hline $\begin{array}{l}\text { 2. The contents of the course were } \\
\text { understandable. }\end{array}$ & 4.0 & 4.3 \\
$\begin{array}{l}\text { 3. I acquired knowledge and skills via the } \\
\text { course. }\end{array}$ & 4.0 & 4.0 \\
$\begin{array}{l}\text { 4. The difficulty of the activities was } \\
\text { appropriate. }\end{array}$ & 4.4 & 4.7 \\
$\begin{array}{l}\text { 5. I am satisfied with the course on the } \\
\text { whole. }\end{array}$ & 4.1 & 4.7 \\
\hline \hline
\end{tabular}

\section{D.Students' Knowledge on Specific topics}

Participants' prior knowledge on specific topics was assessed by counting the number of nodes which they wrote on the pre-semantic networks, while their knowledge at the end of the lesson was assessed by the number of nodes they wrote on the post-semantic networks. Students' advance in knowledge was calculated by subtracting the number of nodes written on the post-semantic networks from the nodes on the pre-semantic networks. The number of nodes on students' semantic networks were aggregated every four weeks, starting from the second week of the semester.

Table 4 shows the time-by time changes in participants' knowledge on specific topics.

TABLE IV PARTICIPANTS' KNOWLEDGE ON SPECIFIC TOPICS

\begin{tabular}{l|r|r|r|r}
\hline \hline & week 2 & week 6 & week 10 & week 14 \\
\hline \hline $\begin{array}{l}\text { Knowledge before the } \\
\text { lesson }\end{array}$ & 7.78 & 7.68 & 6.13 & 6.41 \\
\hline $\begin{array}{l}\text { Knowledge at the end } \\
\text { of the lesson }\end{array}$ & 11.31 & 12.61 & 11.10 & 11.86 \\
\hline $\begin{array}{l}\text { Knowledge increase } \\
\text { (post-pre lesson) }\end{array}$ & 3.53 & 4.93 & 4.97 & 5.45 \\
\hline \hline
\end{tabular}


Table 5 shows the effects of top-down processing in four-skills integrated CALL by comparing participants' knowledge increase of the second week and fourteenth week. Results indicate that participants' knowledge on specific topic significantly increased at the end of the semester $(t(31)=3.76$, $\mathrm{p}<.00)$.

Results suggest that learners' knowledge increases along with their increase in experience of top-down processing four-skills integrated CALL.

TABLE V EFFECTS OF TOP-DOWN PROCESSING ON PARTICIPANTS' KNOWLEDGE ON SPECIFIC TOPIC

\begin{tabular}{l|r|r|r|r|r}
\hline \hline & $\begin{array}{r}\text { week 2, } \\
\text { mean, } \\
\text { (SD) }\end{array}$ & $\begin{array}{r}\text { week 14, } \\
\text { mean, } \\
\text { (SD) }\end{array}$ & $d f$ & $t$ & $P$ \\
\hline \hline & 3.53 & 5.45 & & & \\
Knowledge increase & 3.45 & 3.06 & 31 & 3.76 & $<.00$ \\
\hline \hline
\end{tabular}

\section{V.DISCUSSIONS}

The purpose of the study was to examine the effectiveness of top-down processing in four-skills integrated CALL. Semantic networks were used as tools to activate and construct students' content schemata on the lessons' topics.

Regarding the first research question "What effects do top-down processing have on students' English language proficiency in four-skills integrated CALL?," participants' English language proficiency was significantly higher when they participated in a four-skills integrated CALL course that was operated in a top-down approach.

Moreover, results of participants' pre-post semantic networks show that participants who participated in the four-skills integrated CALL course in a top-down approach increased their knowledge on specific topics week-by week. Results suggest that if learners increase their experience in top-down processing four-skills integrated CALL, they could increase their semantic knowledge.

With regard to the second research question "What effects do top-down processing have on students' attitude in four-skills integrated CALL?," results of the questionnaire survey suggest that students found the CALL course in a top-down approach more interesting, understandable, at an appropriate difficulty, and satisfactory, compared with the CALL course in a bottom-up approach.

\section{CONCLUSION}

Results of the study suggest that top-down processing in four-skills integrated CALL enhances English language proficiency level, knowledge and attitude of Japanese university students at intermediate English proficiency level. Results indicate that top-down processing activates students' content schemata, enables them to elaborate new words/concepts, and enables them to reconstruct their schemata.

Although findings of this study provide pedagogical implications of CALL, they also have few limitations. Since the participants of this study were Japanese students who majored in English culture and their English proficiency level was adequately high, using other samples from other majors, English proficiency level, prior experience of CALL activities is recommended for future generalization. Especially, it is meaningful to investigate the interactions between learners' characteristic and approaches in CALL.

Moreover, participants in this studied English in a four-skills integrated approach. Therefore, it is recommended that future studies examine the effects of top-down processing when English skills are taught separately. In fact, there are many studies that suggest the significance of information processing approaches in reading [30], [31] [32] and listening [33], [34]. Therefore, it $\mathrm{t}$ is especially important to examine the effects of information processing approaches in ELF in the area of productive skills.

\section{ACKNOWLEDGMENT}

This work was supported by JSPS KAKENHI: Grant-in-Aid for Scientific Research (C), Grant Number 16K01139.

\section{REFERENCES}

[1] B. Powell, "The Use of Computer Assisted Language Learning," Forum of Modern Language Studies, vol. 34, no. 2, pp. 184-194, 1998. https://doi.org/10.1093/fmls/XXXIV.2.184

[2] M. Levy, Computer-assisted Language Learning: Context and Conceptualization, Oxford: Clarendon Press, 1972.

[3] M. Warschauer, "Computer Assisted Language Learning: an Introduction," in S. Fotos (ed.) Multimedia language teaching, Tokyo: Logos International, pp. 3-20, 1996.

[4] L. T. Tuan, "Teaching Reading through WebQuest," Journal of Language Teaching and Research, vol. 2, no. 3, pp. 664-673, 2011. https://doi.org/10.4304/jltr.2.3.664-673

[5] M. Saeidi, and M. Yusefi, "The Effect of Computer-Assisted Language Learning on Reading Comprehension in an Iranian EFL Context," in L. Bradley \& S. Thouësny (Eds.), CALL: Using, Learning, Knowing, EUROCALL Conference Proceedings, Gothenburg, Sweden, 2012, (pp. 259-263, 2012.

https://doi.org/10.14705/rpnet.2012.000063

[6] W-L. Chang, and Y-C. Sun, "Scaffolding and Web Concordances as Support for Language Learning," Computer Assisted Language Learning, vol. 22, no. 4, pp. 283-302, 2009.

https://doi.org/10.1080/09588220903184518

[7] R. M. Ambrose, and S. Palpanathan, "Investigating the Effectiveness of Computer-Assisted Language Learning (CALL) Using Google Documents in Enhancing Writing - A study on Senior 1 Students in a Chinese Independent High School," IAFOR Journal of Language Learning, vol. 3, no. 2, pp. 85-112, 2017.

[8] M. J. B. Mayor, "CALL-enhanced L2 Listening Skills-Aiming for Automatization in a Multimedia Environment," Indian Journal of Applied Linguistics, vol. 35, no. 1, pp. 107-120, 2009.

[9] H. Nachoua, "Computer-Assisted Language Learning for Improving Students' Listening Skill," Procedia-Social and Behavioral Sciences, vol. 69, pp.1150-1159, 2012. https://doi.org/10.1016/j.sbspro.2012.12.045

[10] F. Talebi, and N. Teimoury, "The Effect of Computer-assisted Language Learning on Improving EFL Learners' Pronunciation Ability," World Journal of English Language, vol. 3, no. 2, pp. 52-56, 2013. https://doi.org/10.5430/wjel.v3n2p52

[11] J. Poursalehi, M. HabibAboulalaei, and M. Zohrabi, "The Impact of Computer Assisted Language Learning (CALL) on Iranian Learners' Speaking Skill," International Journal of Language Learning and Applied Linguistics World, vol. 7, no. 3, pp. 494-503, 2014. 
[12] A. Mutlu, and B. Eröz-Tŭga, "The Role of Computer-Assisted Language Learning (CALL) in Promoting Learner Autonomy," Eurasian Journal of Educational Research, vol. 51, pp. 107-122, 2013.

[13] A. A. Zarei, and M. Hashemipour, "The Effect of Computer-Assisted Instruction on Improving EFL Learners' Autonomy and Motivation," Journal of Applied Linguistics, vol. 1, no. 1, pp. 40-48, 2015.

[14] C. Yu-lin, "The Impact of Technology-Integrated Instruction to Elementary Students' Language Learning Motivation and Performance," Journal of Literature and Art Studies, vol. 5, no. 8, pp. 679-685, 2015.

[15] A. Ateș, U. Altunay, and E. Altun, "The Effects of Computer Assisted English Instruction on High School Preparatory Students' Attitudes towards Computers and English," Journal of Theory and Practice in Education, vol. 2, no. 2, pp. 97-112, 2006.

[16] D. Zheng, M. F. Young, R. A. Brewer, and M. Wagner, "Attitude and Self-Efficacy Change, English Language Learning in Virtual Worlds," CALICO Journal, vol. 27, no. 1, pp. 205-231, 2009. https://doi.org/10.11139/cj.27.1.205-231

[17] O. Kocaman, and M. İskender, "The Effect of Computer-Assisted Foreign Language Teaching on the Student's Attitude and Success," Journal of Human Sciences, vol. 13, no. 3, pp. 6124-6135, 2016. https://doi.org/10.14687/jhs.v13i3.4346

[18] M. Henderson, H. Huang, S. Grant, L. Henderson, "Language Acquisition in Second Life: Improving Self-Efficacy Beliefs," Proceedings ascilite Auckland 2009, pp. 464-474, 2009.

[19] Ministry of Education, Culture, Sports, Science and Technology, (March 2008), "Course of Study" for Lower Secondary Schools: 8th Edition. [Online].

Available: http://www.mext.go.jp/a_menu/shotou/new-cs/youryou/1304424.htm

[20] Ministry of Education, Culture, Sports, Science and Technology, (March 2009), "Course of Study" for Upper Secondary Schools: 8th Edition. [Online].

Available: http://www.mext.go.jp/a_menu/shotou/new-cs/youryou/1304427.htm

[21] Ministry of Education, Culture, Sports, Science and Technology, (March 1999), "Course of Study" for Upper Secondary Schools: 7th Edition. [Online]. Available: https://www.nier.go.jp/guideline/h10sh/index.htm

[22] Ministry of Education, Culture, Sports, Science and Technology, (March 2017), "Course of Study" for Lower Secondary Schools: 9th Edition. [Online]. Available: http://www.mext.go.jp/component/a_menu/education/micro_detail/_ic sFiles/afieldfile/2017/06/21/1384661_5.pdf

[23] Q. Huang, "Background Knowledge and Reading Teaching," Asian Social Science, vol. 5, no. 5, pp. 138-142, 2009. https://doi.org/10.5539/ass.v5n5p138

[24] D. Nunan, Second Language Teaching and Learning, Boston: Heinle and Heinle, 1999.

[25] E. V. de Debat, "Applying Current Approaches to the Teaching of Reading," English Teaching Forum, no. 1, pp. 8-15, 2006.

[26] P. B. Gough, "One second of reading," in J. F. Kawanagh and I. G. Mattingley (Eds.), Language by ear and by eye. Cambridge, MA: MIT Press, 1972.

[27] P. L. Carrell, and J. C. Eisterhold, "Schema theory and ESL reading pedagogy," in P. L. Carrell, J. Devine, and D. E. Eskey (eds.), Interactive Approaches to Second Language Reading. Cambridge: CUP. https://doi.org/10.1017/CBO9781139524513.010 https://doi.org/10.2307/3586613

[28] V. Škudienè, "A comparison of reading models, their application to the classroom and their impact on comprehension," Studies about Languages, vol. 2, pp. 94-98, 2002.

[29] D. D. Johnson, and P. D. Pearson, Teaching reading vocabulary (2nd ed.), New York: Holt, Reinhart and Winston, 1984

[30] V. Škudienė, "A Comparison of Reading Models, Their Application to the Classroom and Their Impact on Comprehension," Studies about Languages, no. 2, pp. 94-98, 2002.

[31] C. A. Kurby, M. A. Britt, and J. P. Magliano, "The Role of Top-down and Bottom-up Processes in Between-text Integration," Reading Psychology, pp. 335-362, 2005. https://doi.org/10.1080/02702710500285870

[32] A. H. Fatemi, V. S. Vahedi, and Z. S.Seyyedrezaie, "The Effects of Top-down/Bottom-up Processing and Field-dependent/Field-independent Cognitive Style on Iranian EFL Learners' Reading Comprehension," Theory and Practice in Language Studies, vol. 4, no. 4, pp. 686-693, 2014. https://doi.org/10.4304/tpls.4.4.686-693

[33] A. A. Zekveld, D. J. Heslenfleld, J. M. Festen, and R Schoonhoven, "Top-down and Bottom-up Processes in Speech Comprehension," NeuroImage, vol. 32, pp. 1826-1836, 2006. https://doi.org/10.1016/j.neuroimage.2006.04.199

[34] M. K. Pichora-Fuller, Use of Supportive Context by Younger and Older Adult Listeners: Balancing Bottom-up and Top-down Information Processing, International Journal of Audiology, vol. 47, no. 2, pp. 72-82, 2008

https://doi.org/10.1080/14992020802307404.

About Author:

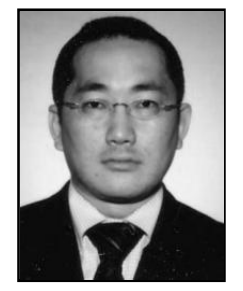

Hiroki Yoshida received the MEd in educational methodology (audio-visual education) from International Christian University in 2001. He taught in the Faculty of Education, Tokoha University from April, 2002 to March, 2017. He is currently a professor at the College of Intercultural Studies, Kanto Gakuin University. His research interests include English education, teacher education, and cooperative learning. 